\title{
Maternal zinc restriction affects postnatal growth and glucose homeostasis in rat offspring differently depending upon adequacy of their nutrient intake
}

\author{
Ming-Yu Jou' ', Bo Lönnerdal' and Anthony F. Philipps ${ }^{2}$
}

INTRODUCTION: We have previously investigated effects of moderate maternal zinc $(Z n)$ restriction on growth and glucose homeostasis in offspring, but interaction between maternal $Z n$ restriction and postnatal nutrition have not been studied.

RESULTS: Weight and serum Zn were lower in ZnD-IN than in $\mathrm{ZnC}$-IN rats at wk 3, but ZnD-AN and ZnD-EN rats had greater weights than respective controls and higher insulin-like growth factor-1 (ZnD-AN) and leptin levels (ZnD-EN). Subsequently, both ZnD-AN and ZnD-EN pups were insulin resistant, and had evidence of elevated serum leptin and depressed insulin receptor phosphorylation with gender-specific differences up to 15 weeks.

DISCUSSION: Maternal Zn restriction interacted with postnatal nutritional status, resulting in divergent effects on weight gain and insulin resistance. Interaction between potential effects of fetal $Z n$ restriction and food availability postnatally may be one factor responsible for later metabolic derangements.

METHODS: Rats were fed $\mathrm{Zn}$ restricted $(\mathrm{ZnD}, 7 \mu \mathrm{g} / \mathrm{g})$ or control $(\mathrm{ZnC}, 25 \mu \mathrm{g} / \mathrm{g})$ diets ad libitum from $3 \mathrm{wk}$ pre-conception to $3 \mathrm{wk}$ post-parturition. Postnatally, litters were culled to 13 (IN, inadequate nutrition), 7 (AN, adequate nutrition), and 4 (EN, excess nutrition) pups/dam, respectively, and nursed by their original mothers. Postweaning, pups were fed rodent diet ad libitum. Tests to assess insulin resistance were performed subsequently.

ncreased prevalence of the insulin resistance syndrome and type 2 diabetes has been noted worldwide, including in both developed and developing countries (1). Different "thrifty fetus" hypotheses $(2,3)$ have been proposed to explain some of the possible causes of the escalating epidemic of diabetes from both genetic and environmental perspectives (4). Evidence from human and animal studies suggests that early nutritional disruption may program long-term metabolic modifications, possibly resulting from either adaptive changes in gene expression and/or preferential clonal selection of adapted cells in programmed tissues (5). The "developmental origins of health and disease" hypothesis proposed by Hales et al. in $1992(3,6)$ suggests that inadequate nutrition (IN) during fetal life causes permanent metabolic modifications in offspring, leading to increased risks of diabetes and cardiovascular diseases in adulthood.

In addition to the demonstrated link between early nutritional programming and development of diabetes and obesity in later life (5), both fetal programming effects (7) and a rapid rate of postnatal catch-up growth are strong predictors of later metabolic diseases such as insulin resistance and obesity (8-12). The influence of nutritional programming on lifetime growth has been shown to occur at critical periods of early life (13). Snoeck et al. have shown that postnatal exposure to a low-protein diet results in permanently decreased body size in animals, whereas prenatal exposure to malnutrition does not have the same effect (14). Data suggest that variation in both fetal and postnatal dietary intake may participate in long-term effects on the development of obesity and diabetes in the offspring.

Dietary zinc $(\mathrm{Zn})$ plays important roles in growth and development (15-17). Increased $\mathrm{Zn}$ requirements during periods of rapid growth (16), such as infancy, adolescence, pregnancy, and lactation, increase the risk for $\mathrm{Zn}$ restriction. The potentially large number of vulnerable pregnant women with mild $\mathrm{Zn}$ restriction worldwide is difficult to estimate but may be a reason for an increase in the development of insulin resistance. In a previous study using a rat model, we observed that maternal $\mathrm{Zn}$ restriction caused impaired glucose sensitivity in the offspring (18). However, effects of differences in postnatal nutrition and interactions between maternal $\mathrm{Zn}$ restriction and postnatal nutritional manipulations on the offspring were not investigated. This study was designed to examine potential links between the thrifty phenotype hypothesis and the development of obesity and diabetes in adulthood and to explore relationships between prenatal $\mathrm{Zn}$ restriction and postnatal dietary sufficiency or excess in the development of these metabolic disorders.

\section{RESULTS}

Weight gain and food intake did not differ between control diet $(\mathrm{ZnC})$ and $\mathrm{Zn}$-restricted diet $(\mathrm{ZnD})$ dams during the study period. There were no differences in litter size $(\mathrm{ZnC}, 14.7 \pm$ 1.6; $\mathrm{ZnD}, 14.0 \pm 1.9)$ or birth weight $(\mathrm{ZnC}, 7.16 \pm 0.83 \mathrm{~g} ; \mathrm{ZnD}$, $6.84 \pm 0.83 \mathrm{~g}$ ) between $\mathrm{ZnC}$ and $\mathrm{ZnD}$ groups. 


\section{Growth of Pups}

$\mathrm{ZnD}$-IN pups weighed significantly less than $\mathrm{ZnC}$-IN pups at wk 1.5 and 3 (roughly $30 \%$ and $18 \%$ less, respectively, Table 1 , $P<0.05$ ). At wk 1.5 and 3, body weight did not differ between $\mathrm{ZnC}-\mathrm{AN}$ and $\mathrm{ZnD}-\mathrm{AN}$ pups, but ZnD-EN pups had significantly higher body weight than $\mathrm{ZnC}$-EN pups (roughly $10 \%$ and $15 \%$ greater, respectively, Table $1, P<0.05)$. No gender differences were observed and so data at wk 1.5 and 3 were pooled (Table 1). Two-way ANOVA indicated significant effects of maternal $\mathrm{Zn}$ restriction $(P=0.002)$ at wk 1.5 and postnatal nutrition $(P<0.0001)$ on body weight and a significant interaction between maternal and postnatal effects $(P<$ 0.0001 ) at wk 1.5 and 3 (Table 1 ).

After the pups were weaned, $\mathrm{ZnD}$-IN males weighed less than ZnC-IN males at wk 5 (Table $1, P<0.05$ ) but not subsequently. Body weight did not significantly differ between $\mathrm{ZnC}-\mathrm{AN}$ and $\mathrm{ZnD}$-AN males or females after weaning (Table 1). ZnD-EN males weighed significantly more than $\mathrm{ZnC}-\mathrm{EN}$ males only at wk 5 (Table 1). However, there were consistent increments in weight of $\mathrm{ZnD}$ females (3-4\%) and males (6-7\%) as compared to $\mathrm{ZnC}$ that remained at wk 10 and 12 , but these were not statistically significant.

Two-way ANOVA indicated no significant effect of maternal $\mathrm{Zn}$ restriction on body weight after weaning; however, there were significant effects of postnatal nutrition status on body weight and significant interactions between maternal and postnatal effects in males at wk 5, 10, and 12 and in females at wk 5 $(P<0.05$, Table 1$)$. Effects of postnatal overnutrition persisted longer in males (wk 12) than in females (wk 10).

\section{Zn Status of Pups}

Serum $\mathrm{Zn}$ levels did not differ between dietary groups at birth $(\mathrm{ZnC}, 56.1 \pm 7.4 \mu \mathrm{mol} / \mathrm{l} ; \mathrm{ZnD}, 55.2 \pm 6.2 \mu \mathrm{mol} / \mathrm{l} ; n=20)$, but $\mathrm{ZnD}$ pups had significantly lower hepatic $\mathrm{Zn}$ concentration $(\mathrm{ZnC}, 1.64 \pm 0.23 \mu \mathrm{mol} / \mathrm{g} ; \mathrm{ZnD}, 1.13 \pm 0.16 \mu \mathrm{mol} / \mathrm{g} ; n=20$, $P<0.05)$ and total liver $\mathrm{Zn}$ content $(\mathrm{ZnC}, 0.44 \pm 0.10 \mu \mathrm{mol}$;
$\mathrm{ZnD}, 0.32 \pm 0.1 \mu \mathrm{mol} ; n=20, P<0.05)$ than respective controls at birth despite similar liver weights.

Significantly lower serum $\mathrm{Zn}$ levels were found in $\mathrm{ZnD}$-IN pups as compared with ZnC-IN pups at wk 3 (Table 2), but not in the adequate nutrition (AN) or excess nutrition (EN) groups. Although $\mathrm{ZnD}-\mathrm{AN}$ and $\mathrm{ZnD}-\mathrm{EN}$ pups had significantly lower liver $\mathrm{Zn}$ concentrations as compared with respective controls at wk 3 (Table $2, P<0.05$ ), notably, the proportion of liver weight relative to total body weight was higher in $\mathrm{ZnD}-\mathrm{AN}$ and $\mathrm{ZnD}-\mathrm{EN}$ pups as compared with controls. This resulted in no significant difference in total liver $\mathrm{Zn}$ content between dietary groups $(\mathrm{ZnC}-\mathrm{AN}, 0.77 \pm 0.09 \mu \mathrm{mol} ; \mathrm{ZnD}-\mathrm{AN}$, $0.73 \pm 0.12 \mu \mathrm{mol} ; \mathrm{ZnC}-\mathrm{EN}, 0.84 \pm 0.13 \mu \mathrm{mol} ; \mathrm{ZnD}-\mathrm{EN}, 0.78 \pm$ $0.16 \mu \mathrm{mol}, n=20)$.

\section{Blood Glucose Level and Serum Parameters}

Blood glucose and serum C-peptide levels were similar in the $\mathrm{ZnC}-\mathrm{IN}$ and $\mathrm{ZnD}$-IN groups; however, maternal $\mathrm{Zn}$ restriction was associated with significantly higher levels of glucose and C-peptide in $\mathrm{ZnD}$-AN and $\mathrm{ZnD}$-EN pups at wk 3 than in the $\mathrm{ZnC}$ groups (Table 2, $P<0.05$ ). Serum insulin concentrations at wk 3 were $50 \%$ higher in $\mathrm{ZnD}$-EN rats as compared with $\mathrm{ZnC}$-EN rats (Table 2). Insulin values for the two AN groups were similar. However, despite this, $\mathrm{ZnD}-\mathrm{AN}$ rats had significantly higher serum insulin-like growth factor-1 (IGF-1) levels than ZnC-AN rats (Table 2), and $\mathrm{ZnD}$-EN rats had significantly greater serum leptin levels than ZnC-EN rats at wk 3 (Table 2). Two-way ANOVA also indicated that there were significant effects of maternal $\mathrm{Zn}$ restriction and postnatal overnutrition and interactions between these effects on leptin levels at wk $3(P<0.05)$.

By wk 15, ZnD-AN and ZnD-EN males, but not females, continued to have significantly higher levels of serum C-peptide, insulin, and leptin than their respective control males (Table 3, $P<0.05$ ), and two-way ANOVA confirmed significant effects of maternal $\mathrm{Zn}$ restriction on blood glucose and serum C-peptide, insulin, and leptin levels only in males (Table 3,

Table 1. Effects of mild maternal Zn restriction and postnatal nutrition on offspring weights at different ages

\begin{tabular}{|c|c|c|c|c|c|c|c|c|c|}
\hline \multicolumn{10}{|c|}{ Weight of pups (g) } \\
\hline & \multirow[b]{2}{*}{ Age } & \multirow[b]{2}{*}{ wk 1.5} & \multirow[b]{2}{*}{ wk 3} & \multicolumn{3}{|c|}{ Males } & \multicolumn{3}{|c|}{ Females } \\
\hline & & & & wk 5 & wk 10 & wk 12 & wk 5 & wk 10 & wk 12 \\
\hline \multirow[t]{2}{*}{$\mathrm{IN}^{\mathrm{a}}$} & $\mathrm{ZnC}$ & $20.3 \pm 2.0$ & $37.3 \pm 3.0$ & $140.3 \pm 7.8$ & $386.9 \pm 20.9$ & $447.0 \pm 28.8$ & $124.0 \pm 4.2$ & $244.4 \pm 20.8$ & $271.6 \pm 20.5$ \\
\hline & $\mathrm{ZnD}$ & $15.4 \pm 0.8^{b}$ & $28.9 \pm 1.7^{b}$ & $117.8 \pm 9.8^{b}$ & $358.7 \pm 18.9$ & $410.2 \pm 26.8$ & $104.7 \pm 5.4$ & $226.8 \pm 6.7$ & $252.2 \pm 8.0$ \\
\hline \multirow[t]{2}{*}{$\mathrm{AN}^{\mathrm{a}}$} & $\mathrm{ZnC}$ & $20.7 \pm 2.1$ & $41.1 \pm 3.0$ & $154.6 \pm 12.3$ & $424.6 \pm 35.3$ & $463.4 \pm 38.3$ & $133.8 \pm 17.7$ & $261.3 \pm 35.1$ & $278.1 \pm 37.4$ \\
\hline & $\mathrm{ZnD}$ & $21.7 \pm 2.0$ & $43.7 \pm 3.0$ & $158.4 \pm 10.2$ & $424.8 \pm 21.6$ & $472.5 \pm 28.5$ & $130.0 \pm 10.9$ & $252.7 \pm 19.0$ & $269.3 \pm 29.0$ \\
\hline \multirow[t]{2}{*}{$\mathrm{EN}^{\mathrm{a}}$} & $\mathrm{ZnC}$ & $22.6 \pm 1.7$ & $45.8 \pm 4.2$ & $154.5 \pm 13.9$ & $436.3 \pm 31.9$ & $499.4 \pm 37.4$ & $130.3 \pm 10.9$ & $251.2 \pm 21.3$ & $277.9 \pm 24.8$ \\
\hline & $\mathrm{ZnD}$ & $24.8 \pm 1.8^{c}$ & $52.6 \pm 5.9^{c}$ & $163.2 \pm 9.6^{c}$ & $462.5 \pm 34.8$ & $533.5 \pm 33.2$ & $140.7 \pm 7.8$ & $260.1 \pm 15.9$ & $288.3 \pm 15.0$ \\
\hline \multicolumn{2}{|c|}{ Maternal Zn ${ }^{d}$} & 0.002 & NS & NS & NS & NS & NS & NS & NS \\
\hline \multicolumn{2}{|c|}{ Postnatal nutrition ${ }^{d}$} & $<0.0001$ & $<0.0001$ & $<0.0001$ & $<0.0001$ & $<0.0001$ & $<0.0001$ & 0.01 & NS \\
\hline \multicolumn{2}{|c|}{ Maternal $\times$ postnatal $^{d}$} & $<0.0001$ & $<0.0001$ & 0.0003 & 0.03 & 0.01 & 0.001 & NS & NS \\
\hline
\end{tabular}

IN, inadequate postnatal nutrition; AN, adequate postnatal nutrition; EN, excess postnatal nutrition; Maternal, pups born from maternal zinc-restricted or control dams; Maternal $\times$ postnatal, maternal zinc restriction and postnatal nutrition interaction; NS, not significant $(P>0.05)$; Postnatal, different postnatal nutrition groups (IN/AN/EN); ZnC, rat pups from control dams; ZnD, rat pups from zinc-restricted dams.

avalues are means \pm s.d., $n=9$. ${ }^{b} Z \mathrm{nD}$-IN values are different from $\mathrm{ZnC}-\mathrm{IN}$. ${ }^{\mathrm{Z}} \mathrm{ZnD}$-EN values are different from ZnC-EN. dP values from two-way ANOVA with maternal Zn restriction and postnatal nutrition status as factors. b,c Different superscript letters indicate significant differences between $Z n C$ and $Z n D$ groups from $t$-test $(P<0.05)$ in different postnatal nutrition groups. 
Table 2. Effects of mild maternal Zn restriction and postnatal nutrition on physiological parameters in the offspring at wk 3

\begin{tabular}{|c|c|c|c|c|c|c|}
\hline & \multicolumn{2}{|c|}{ IN } & \multicolumn{2}{|c|}{ AN } & \multicolumn{2}{|c|}{ EN } \\
\hline & $\mathrm{ZnC}$ & $\mathrm{ZnD}$ & $\mathrm{ZnC}$ & $\mathrm{ZnD}$ & $\mathrm{ZnC}$ & $\mathrm{ZnD}$ \\
\hline Serum Zn, $\mu \mathrm{mol} / \mathrm{l}$ & $20.6 \pm 3.7$ & $14.5 \pm 5.2^{\mathrm{a}}$ & $22.5 \pm 2.6$ & $21.8 \pm 2.6$ & $19.4 \pm 2.0$ & $18.6 \pm 2.8$ \\
\hline Liver Zn, $\mu \mathrm{mol} / \mathrm{g}$ & $0.56 \pm 0.08$ & $0.49 \pm 0.07$ & $0.45 \pm 0.05$ & $0.38 \pm 0.06^{b}$ & $0.44 \pm 0.05$ & $0.38 \pm 0.06^{c}$ \\
\hline Blood glucose, mmol/l & $6.9 \pm 0.6$ & $6.7 \pm 1.3$ & $8.0 \pm 1.3$ & $8.8 \pm 0.7^{b}$ & $7.8 \pm 0.4$ & $8.3 \pm 0.4^{c}$ \\
\hline Serum C-peptide, pmol// & $434 \pm 270$ & $541 \pm 477$ & $501 \pm 335$ & $829 \pm 546^{b}$ & $426 \pm 112$ & $674 \pm 315^{c}$ \\
\hline Serum insulin, pmol/l & - & - & $67 \pm 33$ & $71 \pm 43$ & $40 \pm 9$ & $62 \pm 28^{c}$ \\
\hline Serum IGF-1, nmol/I & - & - & $49.5 \pm 6.6$ & $70.1 \pm 19.7^{b}$ & $58.8 \pm 2.5$ & $56.2 \pm 16.2$ \\
\hline Serum leptin, nmol/l & - & - & $0.10 \pm 0.01$ & $0.11 \pm 0.02$ & $0.21 \pm 0.12$ & $0.36 \pm 0.17^{c}$ \\
\hline
\end{tabular}

Values are means \pm s.d., $n=14$. Data from males and females were pooled.

AN, adequate postnatal nutrition; EN, excess postnatal nutrition; IGF-1, insulin-like growth factor-1; IN, inadequate postnatal nutrition; ZnC, rat pups from control dams; ZnD, rat pups from zinc-restricted dams.

${ }^{a-c}$ Different superscript letters indicate significant differences between $\mathrm{ZnC}$ and $\mathrm{ZnD}$ groups from $t$-test $(P<0.05)$ in different postnatal nutrition groups. ${ }^{\mathrm{Z}} \mathrm{ZnD}$-IN values are different from ZnC-IN. ' ${ }^{\mathrm{ZnD}}$-AN values are different from ZnC-AN. ' ZnD-EN values are different from ZnC-EN.

Table 3. Effects of mild maternal Zn restriction and postnatal nutrition on physiological parameters in the offspring at wk 15

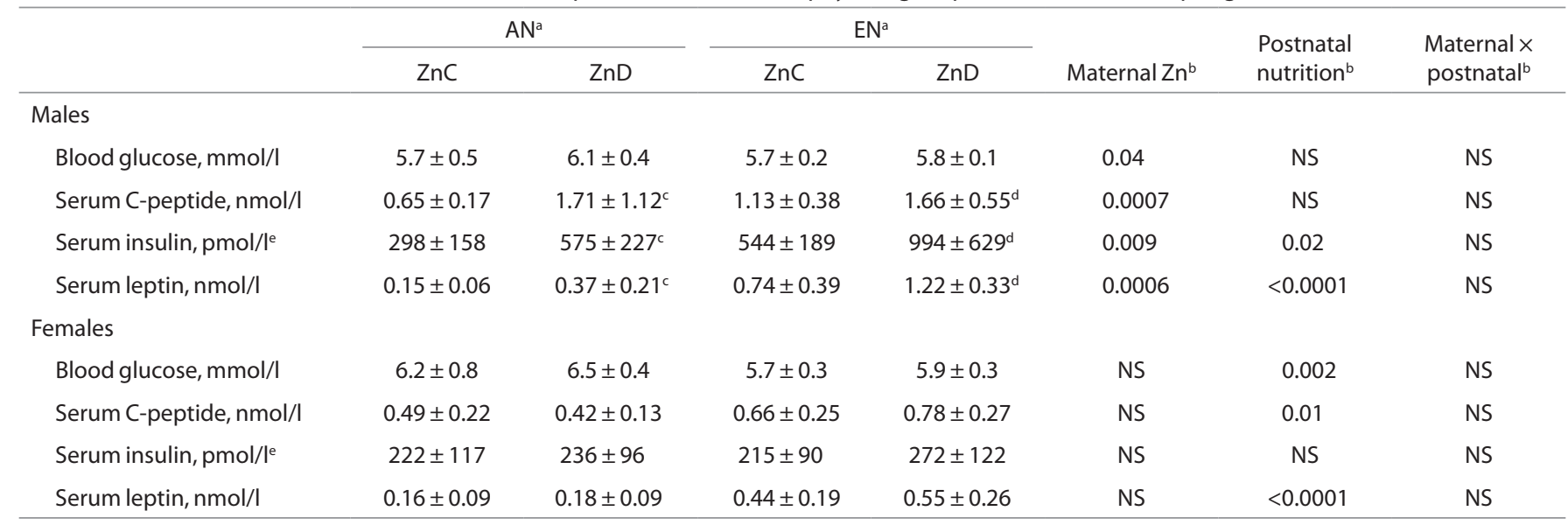

AN, adequate postnatal nutrition; EN, excess postnatal nutrition; IN, inadequate postnatal nutrition; Maternal, pups born from maternal zinc-restricted or control dams; Maternal $\times$ postnatal, maternal zinc restriction and postnatal nutrition interaction; NS, not significant ( $P>0.05$ ); Postnatal, different postnatal nutrition groups (AN/EN); ZnC, rat pups from control dams; ZnD, rat pups from zinc-restricted dams.

avalues are means \pm s.d., $n=9$. ${ }^{b} P$ values from two-way ANOVA with maternal Zn restriction and postnatal nutrition status as factors. ${ }^{c, d}$ Different superscript letters indicate significant differences between $Z n C$ and $Z n D$ groups from $t$-test $(P<0.05)$ in different postnatal nutrition groups. $Z \mathrm{ZnD}$-AN values are different from $Z n C-A N$. ${ }^{d} Z n D$-EN values are different from ZnC-EN. eSerum insulin level was measured after a $4 \mathrm{~h}$ food-deprivation period; the rest of the values were determined after a $12-14 \mathrm{~h}$ food-deprivation period.

$P<0.05)$. Blood glucose and serum C-peptide and leptin levels did not differ between $\mathrm{ZnC}$ and $\mathrm{ZnD}$ females (Table 3). Moreover, two-way ANOVA indicated that postnatal overnutrition was associated with increased leptin levels in both male and female offspring of $\mathrm{ZnD}$ mothers relative to controls at wk 15 (Table 3, $P<0.0001$ ).

\section{Insulin Sensitivity}

Baseline glucose and insulin levels of female and male rats did not differ between $\mathrm{ZnC}$ and $\mathrm{ZnD}$ rats at wk 10. The fold change in blood glucose values following insulin tolerance test (ITT) and glucose tolerance test (GTT) in pups from IN (a), AN (b), and EN (c) groups are shown in Figures 1 (ITT) and 2 (GTT), which represent results of males (left panel) and females (right panel). Blood glucose levels during ITT and GTT did not differ between $\mathrm{ZnC}$-IN and $\mathrm{ZnD}-\mathrm{IN}$ groups in either gender (Figures 1a and 2a). Of note, $\mathrm{ZnD}-\mathrm{AN}$ and $\mathrm{ZnD}$-EN males had significantly higher blood glucose levels at $10 \mathrm{~min}$ during
ITT than their respective controls, and $\mathrm{ZnD}-\mathrm{AN}$ and $\mathrm{ZnD}-\mathrm{EN}$ females exhibited significantly higher levels of blood glucose at 10,20 , and $60 \mathrm{~min}$ than their respective controls (Figure $1 \mathrm{~b}, \mathrm{c}$ ). During GTT, both $\mathrm{ZnD}-\mathrm{AN}$ and $\mathrm{ZnD}-\mathrm{EN}$ males and females had significantly higher blood glucose levels at $30 \mathrm{~min}$ than their respective controls. $\mathrm{ZnD}-\mathrm{AN}$ males and $\mathrm{ZnD}-\mathrm{EN}$ males and females had significant greater blood glucose levels at 45 and $60 \mathrm{~min}$ after glucose injection than their respective controls (Figure 2b,c). Serum insulin levels were measured at 0, 10, 20, and $30 \mathrm{~min}$ after glucose stimulation, but no differences between groups were found.

\section{Immunoblotting of Akt Phosphorylation}

In general, maternal $\mathrm{Zn}$ restriction was associated with moderate suppression of insulin signaling in AN and EN rats by wk 15. Specifically, in liver, phosphorylation of Akt1/2/3 in $\mathrm{ZnD}-\mathrm{AN}$ and $\mathrm{ZnD}-\mathrm{EN}$ females of $15 \mathrm{wk}$ age was significantly lower than in the respective control females (Figure 3a,b). 

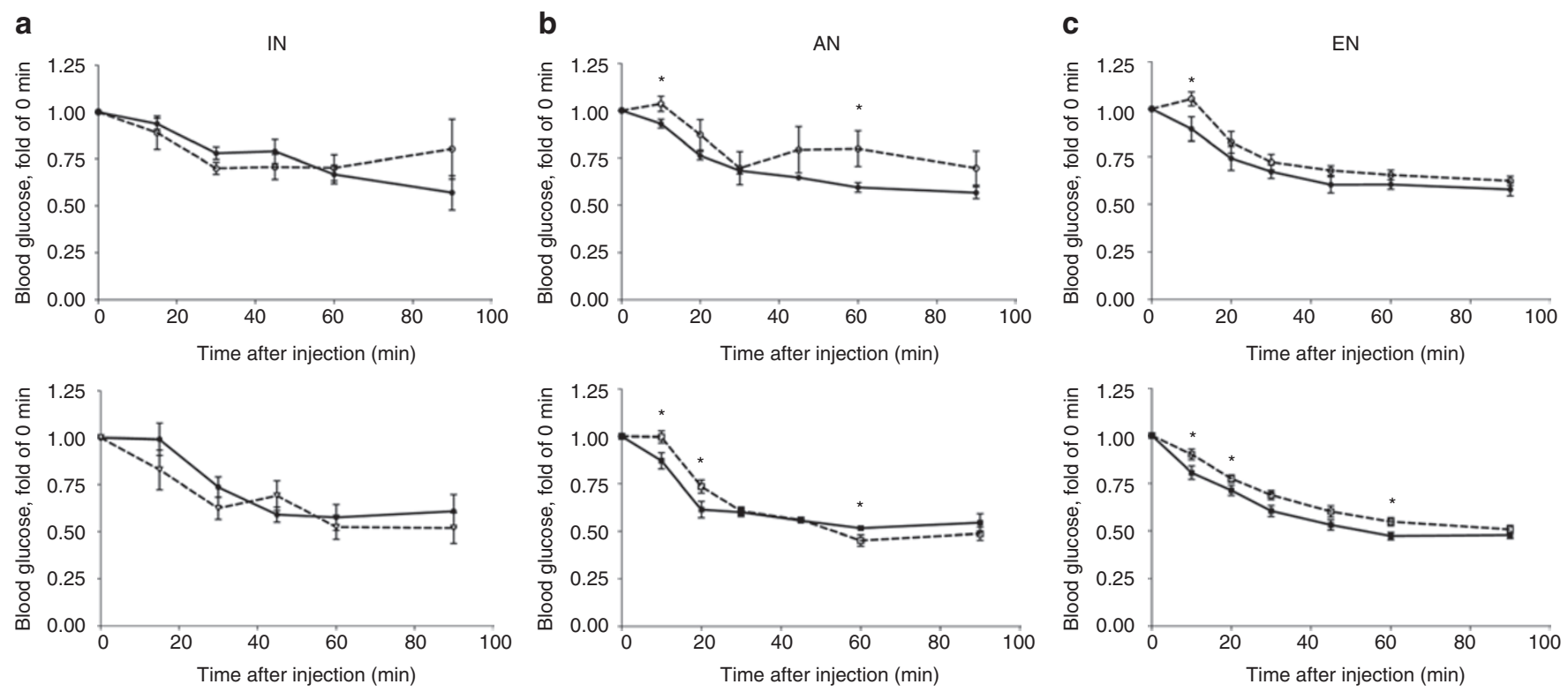

Figure 1. Effects of mild maternal Zn deficiency on insulin tolerance test (ITT) in the offspring with different postnatal nutrition status, inadequate nutrition (IN, a), adequate nutrition (AN, b), and excess nutrition (EN, c). Results are expressed as mean folds of fasting blood glucose concentration of rats. Data from males/females at wk 10 are shown in top/bottom panels, respectively. Both males and females exhibited decreased insulin sensitivity in ZnD-AN and ZnD-EN rats at wk 10. $\bullet, \mathrm{ZnC}$ male; $0, \mathrm{ZnD}$ male; $\mathbf{Q}, \mathrm{ZnC}$ female; $\mathbf{\square}, \mathrm{ZnD}$ female. Data are means $\pm \mathrm{SEM}$. ${ }^{*}$ Significant difference between dietary groups $(P<0.05), n=4-11$.

a
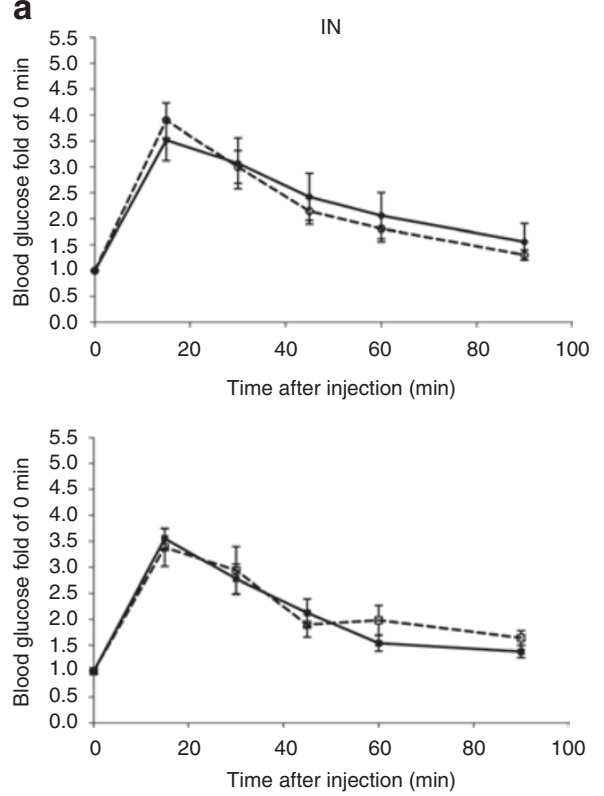

b
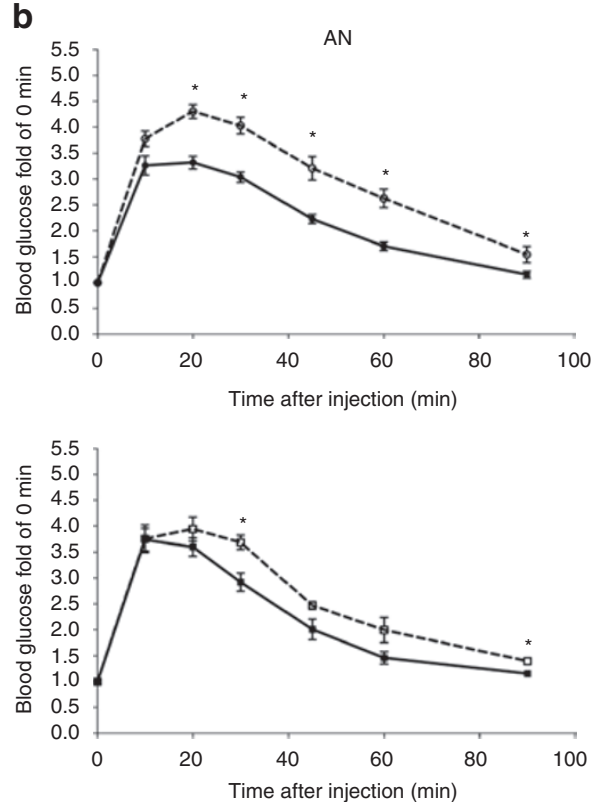

C
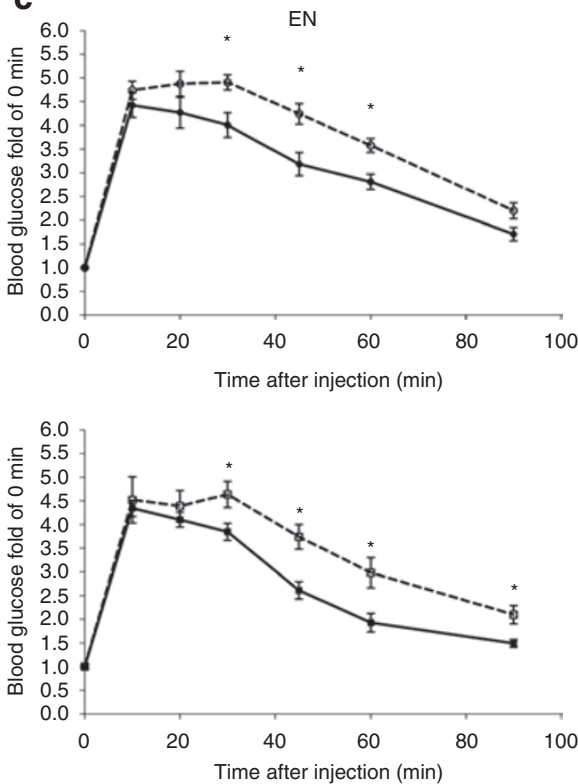

Figure 2. Effects of mild maternal Zn deficiency on glucose tolerance (GTT) in the offspring with different postnatal nutrition status, inadequate nutrition (IN, a), adequate nutrition (AN, b), and excess nutrition (EN, c). Results were expressed as mean percentages of fasting blood glucose concentration of rats. Data from males/females at wk 10 are shown in top/bottom panels, respectively. Decreased glucose sensitivity was found in male and female $\mathrm{Zn}$ restricted rats of $\mathrm{AN}$ and $\mathrm{EN}$ groups at wk $10 . \bullet, \mathrm{ZnC}$ male; $\odot, \mathrm{ZnD}$ male; $\mathbf{\square}, \mathrm{ZnC}$ female; $\square, \mathrm{ZnD}$ female. Data are means \pm SEM. ${ }^{*}$ Significant difference between dietary groups $(P<0.05), n=5-9$.

In liver of males, phosphorylation of Akt1/2/3 was significantly lower than in $\mathrm{ZnC}$-EN rats only in $\mathrm{ZnD}$-EN rats, but phosphorylation of Akt1/2/3 did not differ between ZnC-AN and $\mathrm{ZnD}$-AN males (Figure 3a,b). Total insulin receptor and extracellular signal-regulated kinase $1 / 2$ phosphorylation did not differ between $\mathrm{ZnC}$ and $\mathrm{ZnD}$ females or males in the $\mathrm{AN}$ and EN groups (data not shown).

\section{DISCUSSION}

A rapid rate of postnatal catch-up growth is closely related to later metabolic diseases, such as insulin resistance and obesity. Due to the multifunctional roles of $\mathrm{Zn}$ in physiological pathways, the effects of maternal $\mathrm{Zn}$ restriction on growth and insulin resistance, as well as its interaction with postnatal nutritional status, may be significant. 


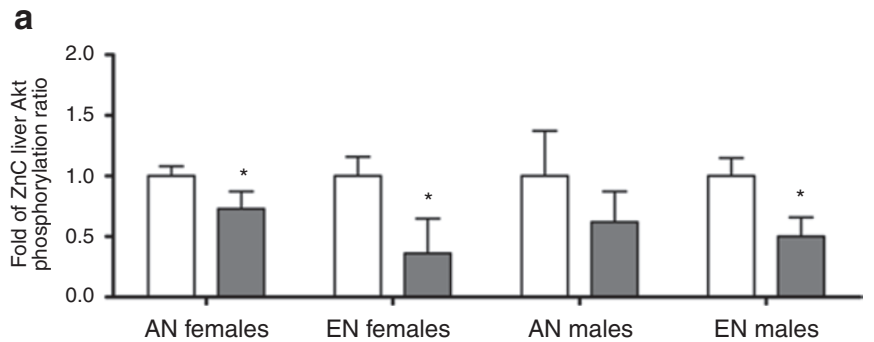

b

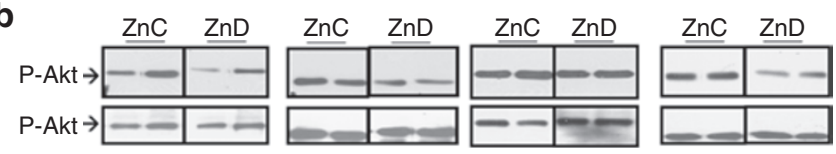

Figure 3. Effects of mild maternal zinc deficiency on suppression of hepatic insulin signaling. (a) Phosphorylation of liver Akt1/2/3 after insulin stimulation in $\mathrm{ZnC}$ (open bars) and $\mathrm{ZnD}$ (filled bars) for AN and EN male and female rat pups at wk 15 of age. The phosphorylation ratio of Akt1/2/3 was calculated as phosphorylated/total (P-/T-) protein densities, and the relative phosphorylation ratio of $\mathrm{ZnD}$ group is presented as the fold of $\mathrm{ZnC}$ group. Values are means \pm s.d., $n=3$ for each of the eight treatment and control groups. *Different from $\mathrm{ZnC}, p<0.05$. AN, adequate nutrition; EN, excess nutrition; $\mathrm{Znc}$, control diet; $\mathrm{ZnD}$, zinc-restricted diet.

\section{Maternal Zn Restriction Interacting with Postnatal Nutrition Differentially Affected Postnatal Growth and Insulin Resistance in the Offspring}

Adult body weight has been shown to be affected by IN during the suckling period, suggesting that nutritional programming of growth occurs during critical periods of early life (13). In this study, the interaction between maternal $\mathrm{Zn}$ restriction and postnatal nutrition resulted in divergent effects on growth of the offspring. Although some studies on rats indicated that gestational caloric deprivation might affect the development of obesity in adulthood $(19,20)$, rapid postnatal growth has been consistently associated with an increased incidence of obesity later in life $(8,21)$. In this study, subsequent overweight in pups born to $\mathrm{Zn}$-restricted dams who were not calorically deprived was induced only in the postnatally overfed group. This suggests a significant interaction between postnatal overnutrition and prenatal $\mathrm{Zn}$ restriction on the offspring's development of obesity.

Links between poor fetal growth, catch-up postnatal growth, and subsequent development of insulin resistance/diabetes in adulthood have been suggested based on evidence from epidemiological and animal studies $(6,8,11-14,22)$. We found a state of insulin resistance in the offspring born to $\mathrm{Zn}$-restricted rats in the adequate/excess postnatal nutrition animals but not in the postnatal undernutrition group, suggesting that maternal $\mathrm{Zn}$ restriction is not an independent factor in the development of insulin resistance.

\section{Overweight and Increased Leptin Levels in Postnatally Overfed Rats Born to Zn-Restricted Dams Were Sex Dependent}

In this study, significant interactions between maternal $\mathrm{Zn}$ restriction and postnatal nutrition affected offspring growth with gender-specific differences, whereby more significant interactions were found in males than in females (Table 1, at wk 12). Male offspring exhibited more pronounced and long-term overweight than females, and a significant graded increase in body weight was observed especially in males born to Zn-restricted dams (Table 1). Comparable data were found in one study using rats undernourished during early gestation, where only males exhibited differences in food intake and body weight later in life (20), The authors suggested that effects of early nutritional manipulations on postnatal growth were sex dependent. In our study, significantly higher leptin levels were found in males born to $\mathrm{Zn}$-restricted dams than in their respective controls at wk 15 (i.e., early adulthood) especially in the postnatal overnutrition group. Although there were no significant interactions between effects of maternal $\mathrm{Zn}$ restriction and postnatal overnutrition on leptin levels in our male rats, potential mechanisms behind the sex-specific relationship among leptin levels, early nutritional status, and the development of obesity should be explored further.

Although circulating leptin levels are positively correlated with fat mass (obesity) in adults, it is unknown if high leptin levels are causative in the development of obesity, because of potential feedback inhibition mechanisms and multiple functions of leptin in control of metabolism. Leptin participates in maturation of the secretion of neuroendocrine hormones in neonates $(23,24)$, such as neuropeptide $\mathrm{Y}$ and pro-opiomelanocortin, that are related to appetite (25), energy balance, body composition $(24,26)$, and neonatal survival (27). Germane to our work are several studies in animals that have suggested that not only leptin itself, but also its indirect actions on hypothalamic regulation, may participate in the prevention of obesity. Taken together, increased leptin secretion in Zn-restricted males at wk 3 and 15 might alter appetite and contribute to the development of overweight in early life. However, food intake was not monitored in our study, and thus we cannot exclude the possibility of differential effects of $\mathrm{Zn}$ deficiency upon appetite.

\section{Maternal Zn Restriction and Its Interaction With Postnatal Overnutrition-Impaired Insulin Receptor Signaling in the Offspring}

Sex-specific effects of maternal $\mathrm{Zn}$ restriction on insulin signaling cascades (decreased Akt phosphorylation) in skeletal muscle of female offspring were demonstrated in our previous study (18), and similar effects on liver insulin signaling in female offspring with adequate postnatal nutrition (AN group) were observed in this study. Furthermore, maternal $\mathrm{Zn}$ restriction was associated with the depression of hepatic insulin signaling in both male and female offspring in the postnatally overfed group (EN group), suggesting that the combination of maternal $\mathrm{Zn}$ restriction and excess available calories/nutrients postnatally may impair downstream insulin signaling.

Although changes of insulin signaling cascades in pancreas were not examined in this study, we speculate that the combination of maternal $\mathrm{Zn}$ restriction and increased postnatal caloric intake might induce a subsequent interruption of insulin receptor trafficking in $\beta$ cells of maternal $\mathrm{Zn}$-restricted rats. A tissue-specific knockout of the insulin receptor at the level of the $\beta$ cell in mice has been reported and was shown to have alterations in insulin secretion in response to glucose and a progressive impairment of glucose tolerance (28). 
Phosphatidylinositol 3-OH kinase and other intermediates in the insulin receptor signaling pathway are potential additional targets for inducing abnormalities due to pre- and postnatal nutritional insults (29).

\section{Conclusions}

Prenatal $\mathrm{Zn}$ restriction, as may occur in vulnerable human populations during pregnancy, was induced in pregravid rats in this study. Offspring of these dams reacted to experimental diets in differing ways, depending on their level of postnatal nutrition. In particular, in contrast to rats delivered from control mothers, those born to Zn-restricted dams and fed to excess during the early postnatal period went on to develop insulin resistance as young adults. Gender-specific changes were also noted, but the $\mathrm{Zn}$-related mechanisms associated with these changes have not yet been uncovered. Recently, Caballero (30) noted a significant inverse relationship between gross domestic product in developing countries and the percentage of households in these countries having both under(usually children) and overweight (usually adults) family members. This and other reports have called attention to the rising proportion of underweight infants and subsequent prevalence of adult obesity. Our study suggests that one potential mechanism for insulin resistance in this vulnerable population may be maternal $\mathrm{Zn}$ restriction.

\section{METHODS \\ Rats}

The study was conducted under the auspices of Animal Resource Services of the University of California, Davis, (UC Davis Institutional Animal Care and Use Committee) accredited by the American Association for the Accreditation of Laboratory Animal Care. Virgin female Sprague Dawley rats $(n=40 ; 7-8 \mathrm{wk})$ were obtained from Charles River (Wilmington, MA), housed in plastic hanging cages under constant conditions (temperature $22^{\circ} \mathrm{C}$; humidity 65\%) with a 12-h dark:light cycle and allowed to consume food ad libitum. After a 3-d acclimatization period, rats were randomly assigned to one of two experimental diets (Figure 4). The Zn-deficient pregnant rat model has been developed previously in our laboratory (18). The $\mathrm{Zn}$-adequate control group $(\mathrm{ZnC} ; n=20)$ was fed a semipurified diet containing $25 \mathrm{mg} \mathrm{Zn} / \mathrm{kg}$ of diet, whereas the $\mathrm{Zn}$-restricted group $(\mathrm{ZnD} ; n=20)$ received a diet marginally restricted in $\mathrm{Zn}(7 \mathrm{mg} \mathrm{Zn} / \mathrm{kg}$ of diet). Rats were fed these diets from 3-wk preconception to 3-wk postparturition (weaning).

On postnatal day 2, pups were culled to 4 pups (EN), 7 pups (AN), or 13 pups (IN) per litter. Weight of pups was monitored, and half of pups were killed at $3 \mathrm{wk}$ after $4 \mathrm{~h}$ of food deprivation. The remaining pups were separated by gender, weaned, and fed standard nonpurified rodent diet (LabDiet 5001; PMI, St. Louis, MO). For signaling experiments, the rats were injected intraperitoneally with 8 units/ $\mathrm{kg}$ of insulin (Humulin R; Eli Lilly, Indianapolis, IN) after $12-14 \mathrm{~h}$ of

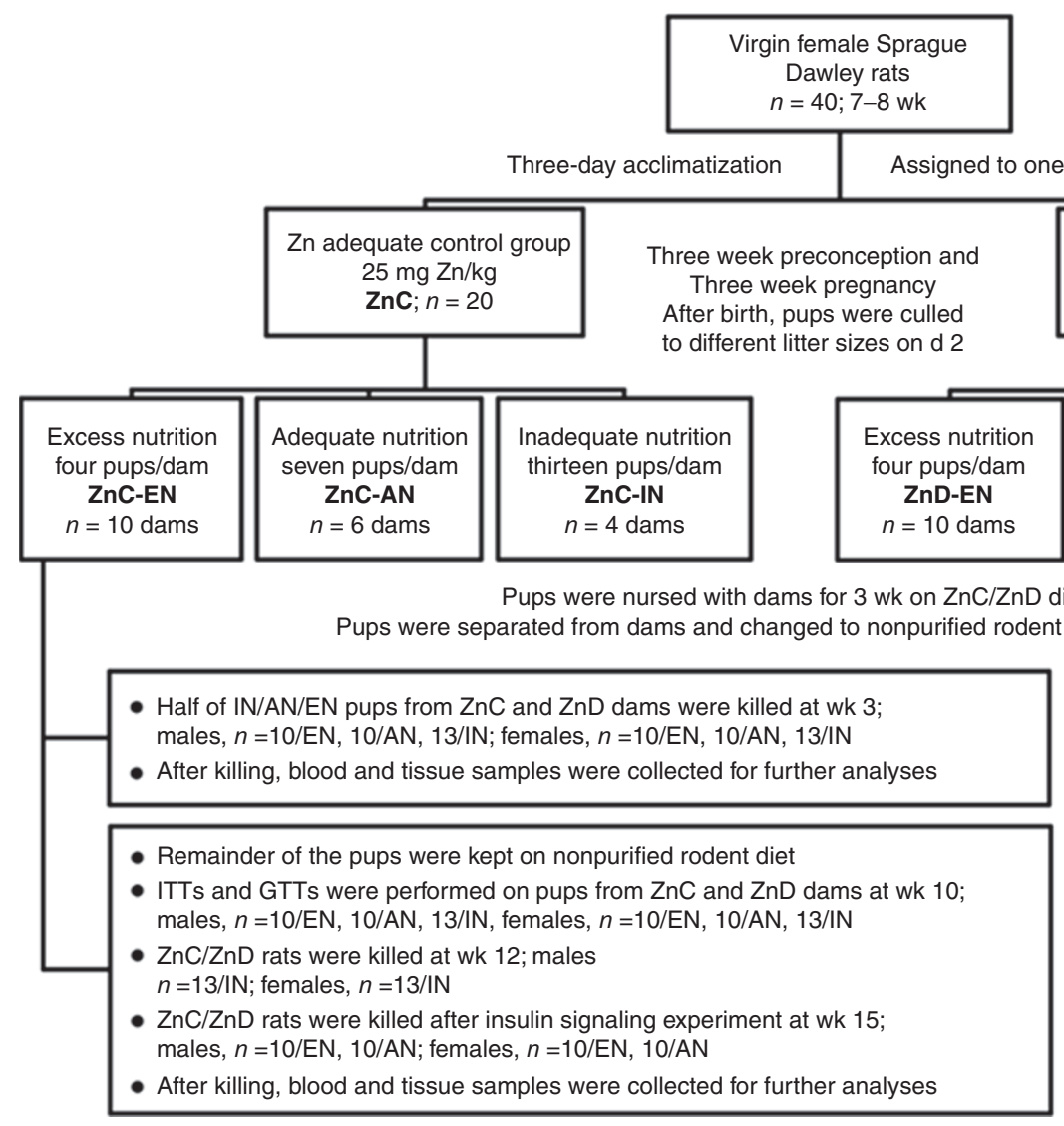

Figure 4. Study design, demonstrating number of rats in each group that were fed zinc ( $\mathrm{Zn}$ ) adequate control diet ( $\mathrm{ZnC}, 25 \mathrm{mg} \mathrm{Zn} / \mathrm{kg}$ diet) or $\mathrm{Zn}$-restricted $\operatorname{diet}(\mathrm{ZnD}, 7 \mathrm{mg} \mathrm{Zn/kg} \mathrm{diet)} \mathrm{throughout} \mathrm{the} \mathrm{study.} \mathrm{After} \mathrm{birth,} \mathrm{litters} \mathrm{were} \mathrm{culled} \mathrm{down} \mathrm{to} \mathrm{different} \mathrm{postnatal} \mathrm{groups} \mathrm{(excess} \mathrm{nutrition} \mathrm{(EN),} 4$ pups/dam; adequate nutrition (AN), 7 pups/dam; inadequate nutrition (IN), 13 pups/dam), and there were six postnatal groups. Pups were nursed with their dams fed $\mathrm{ZnC/ZnD}$ diets during lactation, half of pups from each postnatal groups were killed at age of $3 \mathrm{wk}$, and the remainder were separated from their dams and given nonpurified rodent diet. Insulin and glucose tolerance tests (ITT, GTT) were performed at $10 \mathrm{wk}$ of age. 
food deprivation. The rats were killed $10 \mathrm{~min}$ after injection, and tissues were removed and snap-frozen.

Insulin and Glucose Tolerance Tests (ITTs and GTTs)

ITTs were performed after $4 \mathrm{~h}$ of food deprivation at $10 \mathrm{wk}$. Rats $(n=$ 5-10 of each gender per group) were briefly removed from their cages for tail blood sampling, and glucose concentrations were measured with a glucose meter (Easycheck; Home Aide Diagnostics, Deerfield Beach, FL). Rats were injected intraperitoneally with insulin at a dosage of 0.8 units $/ \mathrm{kg}$ of Humulin R at the age of $10 \mathrm{wk}$. In this test, blood glucose from tail blood was sampled at $0,10,20,30,45,60$, and $90 \mathrm{~min}$ after insulin injection. After a 3 -d period of acclimation following the ITT, GTTs were performed on the same rats after $12-15 \mathrm{~h}$ of food deprivation. Rats were injected intraperitoneally with a glucose solution at a concentration of $200 \mathrm{~g} / \mathrm{l}$ and received $2 \mathrm{~g} / \mathrm{kg}$ of glucose (i.e., $0.2 \mathrm{~g} / 100 \mathrm{~g}$ or $1 \mathrm{ml} / 100 \mathrm{~g}$ body weight, Sigma-Aldrich, St. Louis, MO). Blood for glucose analysis was sampled at the same time points after glucose injection as in the ITT.

\section{Mineral Analysis}

The $\mathrm{Zn}$ contents of diets and tissues were analyzed by flame atomic absorbance spectrometry as previously described $(18,31)$ using a SOLAAR $M$ series atomic absorbance spectrometer (Thermo Electron, Waltham, MA).

\section{Insulin, C-Peptide, Leptin, and IGF-1 Assays}

Serum insulin, C-peptide, and leptin concentrations were measured with commercial RIA kits (Sensitive rat insulin RIA kit, rat C-peptide RIA kit, and rat leptin RIA kit, Linco Research, St. Charles, MO). Serum IGF-1 concentrations were measured with a commercial kit (IGF-1 high sensitive ELISA kit; IDS, Boldon, UK).

\section{Immunoblotting of Akt Phosphorylation}

Immunoblotting of Akt phosphorylation in liver was performed with rabbit polyclonal specific antibodies as previously described (18).

\section{Data Analysis}

Data are expressed as means \pm s.d. and analyzed by two-way ANOVA (with maternal $\mathrm{Zn}$ restriction and postnatal nutrition manipulations as factors). When significant interactions were found, differences across the groups were determined by one-way ANOVA. Post hoc comparisons between $\mathrm{Zn}$ control and restricted groups (for each postnatal nutrition group) were made with a Student's $t$-test. Statistical analysis was conducted using GraphPad Prism 4, and significance was demonstrated at $P<0.05$.

\section{STATEMENT OF FINANCIAL SUPPORT}

This study was supported by the Children's Miracle Network.

Disclosure: The authors have no conflicts of interest to declare.

\section{REFERENCES}

1. King H, Aubert RE, Herman WH. Global burden of diabetes, 19952025: prevalence, numerical estimates, and projections. Diabetes Care 1998;21:1414-31.

2. Neel JV. Diabetes mellitus: a "thrifty" genotype rendered detrimental by "progress"? Am J Hum Genet 1962;14:353-62.

3. Hales CN, Barker DJ. The thrifty phenotype hypothesis. Br Med Bull 2001;60:5-20.

4. Yajnik CS. Nutrition, growth, and body size in relation to insulin resistance and type 2 diabetes. Curr Diab Rep 2003;3:108-14.

5. Lucas A. Programming by early nutrition: an experimental approach. J Nutr 1998;128(2 Suppl):401S-6S.

6. Hales CN, Barker DJ. Type 2 (non-insulin-dependent) diabetes mellitus: the thrifty phenotype hypothesis. Diabetologia 1992;35:595-601.

7. Jones RH, Ozanne SE. Fetal programming of glucose-insulin metabolism. Mol Cell Endocrinol 2009;297:4-9.
8. Ekelund U, Ong KK, Linné Y, et al. Association of weight gain in infancy and early childhood with metabolic risk in young adults. J Clin Endocrinol Metab 2007;92:98-103.

9. Ong KK. Size at birth, postnatal growth and risk of obesity. Horm Res 2006;65:Suppl 3:65-9.

10. Ong KK, Loos RJ. Rapid infancy weight gain and subsequent obesity: systematic reviews and hopeful suggestions. Acta Paediatr 2006;95: 904-8.

11. Singhal A, Fewtrell M, Cole TJ, Lucas A. Low nutrient intake and early growth for later insulin resistance in adolescents born preterm. Lancet 2003;361:1089-97.

12. Bhargava SK, Sachdev HS, Fall CH, et al. Relation of serial changes in childhood body-mass index to impaired glucose tolerance in young adulthood. N Engl J Med 2004;350:865-75.

13. McCance RA. Food, growth, and time. Lancet 1962;2:671-6.

14. Snoeck A, Remacle C, Reusens B, Hoet JJ. Effect of a low protein diet during pregnancy on the fetal rat endocrine pancreas. Biol Neonate 1990;57:107-18.

15. MacDonald RS. The role of zinc in growth and cell proliferation. J Nutr 2000;130(5S Suppl):1500S-8S.

16. Hambidge M. Human zinc deficiency. J Nutr 2000;130(5S Suppl):1344S-9S.

17. Solomon A, Rosenblum G, Gonzales PE, et al. Pronounced diversity in electronic and chemical properties between the catalytic zinc sites of tumor necrosis factor-alpha-converting enzyme and matrix metalloproteinases despite their high structural similarity. J Biol Chem 2004;279:31646-54.

18. Jou MY, Philipps AF, Lönnerdal B. Maternal zinc deficiency in rats affects growth and glucose metabolism in the offspring by inducing insulin resistance postnatally. J Nutr 2010;140:1621-7.

19. Stephens DN. Growth and the development of dietary obesity in adulthood of rats which have been undernourished during development. $\mathrm{Br} \mathrm{J}$ Nutr 1980;44:215-27.

20. Jones AP, Friedman MI. Obesity and adipocyte abnormalities in offspring of rats undernourished during pregnancy. Science 1982;215:1518-9.

21. Monteiro PO, Victora CG. Rapid growth in infancy and childhood and obesity in later life-a systematic review. Obes Rev 2005;6:143-54.

22. Yeung MY. Postnatal growth, neurodevelopment and altered adiposity after preterm birth-from a clinical nutrition perspective. Acta Paediatr 2006;95:909-17.

23. Proulx K, Richard D, Walker CD. Leptin regulates appetite-related neuropeptides in the hypothalamus of developing rats without affecting food intake. Endocrinology 2002;143:4683-92.

24. Davidowa H, Plagemann A. Different responses of ventromedial hypothalamic neurons to leptin in normal and early postnatally overfed rats. Neurosci Lett 2000;293:21-4.

25. Cripps RL, Martin-Gronert MS, Ozanne SE. Fetal and perinatal programming of appetite. Clin Sci 2005;109:1-11.

26. Plagemann A. Perinatal nutrition and hormone-dependent programming of food intake. Horm Res 2006;65:Suppl 3:83-9.

27. Mistry AM, Swick A, Romsos DR. Leptin alters metabolic rates before acquisition of its anorectic effect in developing neonatal mice. Am J Physiol 1999;277(3 Pt 2):R742-7.

28. Kulkarni RN, Brüning JC, Winnay JN, Postic C, Magnuson MA, Kahn CR. Tissue-specific knockout of the insulin receptor in pancreatic beta cells creates an insulin secretory defect similar to that in type 2 diabetes. Cell 1999;96:329-39.

29. Pigeau GM, Kolic J, Ball BJ, et al. Insulin granule recruitment and exocytosis is dependent on p110gamma in insulinoma and human beta-cells. Diabetes 2009;58:2084-92.

30. Caballero B. A nutrition paradox-underweight and obesity in developing countries. N Engl J Med 2005;352:1514-6.

31. Clegg MS, Lönnerdal B, Hurley LS, Keen CL. Analysis of whole blood manganese by flameless atomic absorption spectrophotometry and its use as an indicator of manganese status in animals. Anal Biochem 1986;157:12-8. 